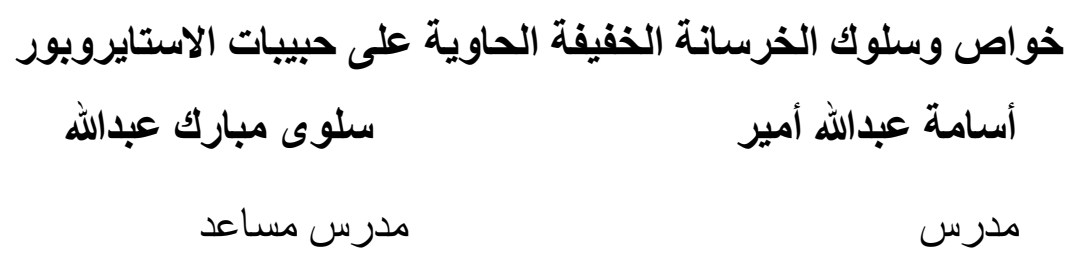

جامعة الموصل/كلية الهندسة/قسم الهندسة المدنية

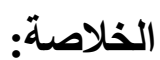

في هذا البحث تم استخدام حبيبات الاستايروبور لإضافتها إلى الخرسانة لعمل ستة آلواح

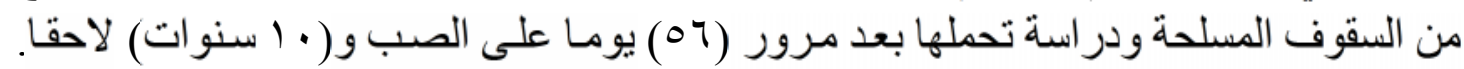

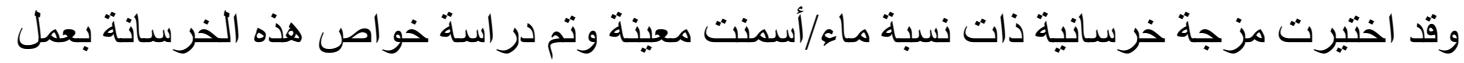

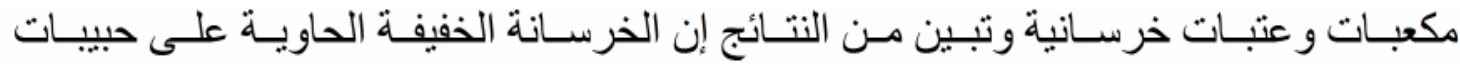
الاستايروبور يمكن استخدامها كبلوكات للبناء بالإضـافة إلى عمل شر ائح سقوف مسلحة مسبقة

\title{
Properties and Behaviour of Lightweight Concrete Containing Polystyrene Granulars
}

Salwa Mubark Abdullah

Assistant Lecturer
Usama Abdullah Ameer

Lecturer

\section{SUMMARY}

In the current research polystyrene particles are added to the concrete mix to produce six strips of reinforced slabs, in order to 
study the strips bearing capacity at the age of 56 days then later at 10 years. A selected mix of specific $\mathrm{w} / \mathrm{c}$ is used; the main properties of the mix were studied from the results of casting cubes and beams. The results indicated that the L.W.C containing the polystyrene particles may be used to manufacture reinforced slab strips, in addition and as a by product to fabricate precast building blocks.

Keyword : Light Concrete, Properties, Polystyrene Granulars

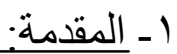

إن الزيـادة الحاصلة في السكان وتتـوع الحاجـة إلى الأبنيـة مـع الأخذ بنظر الاعتبـار

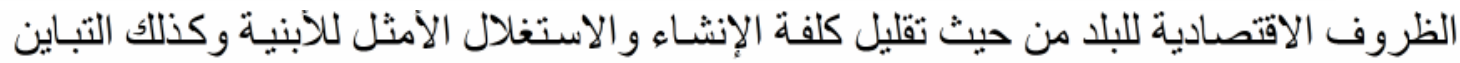

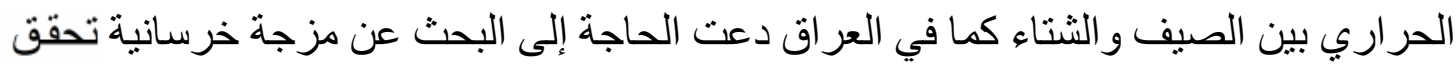

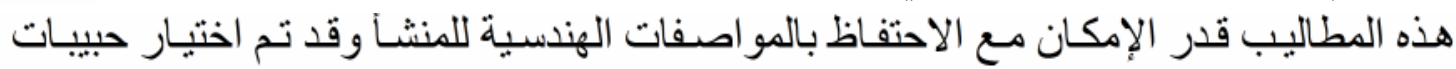

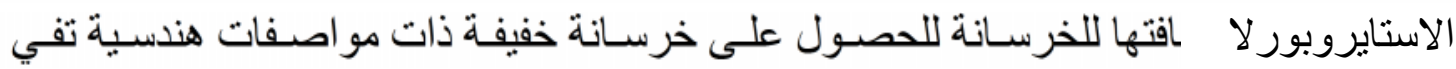
بالمتطلبات الإنشائية بالإضافة إلى العزل الحر ارئ لإي و الصوتي.

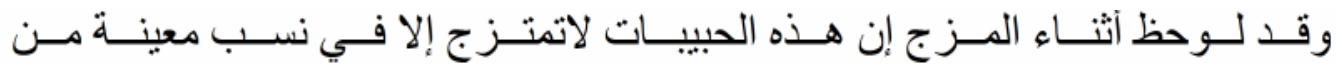

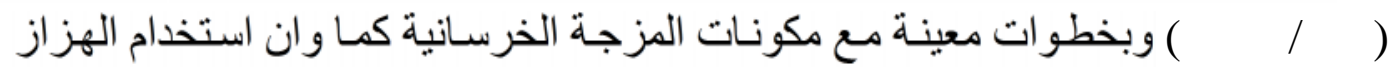
الداخلي في عملية الصب يعتبر فانشلا لانه يعمل على عزل حبين حبيات الاستايروبور. 


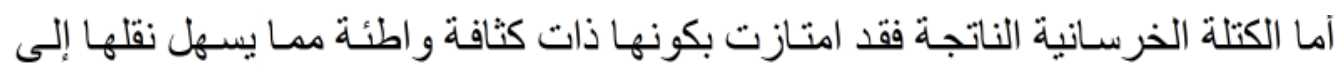

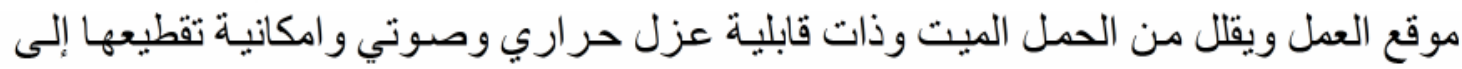
أنشكال منتظمة بسهولة بالإضافة إلى مقاومة انضغاط تفي بلئ بمتطلبات أبنية السكن العادية.

تعتبر حبيبات الاستايروبور ذات كثافة خفيفة مقارنة مع غير هـا من المواد إذا تتراوح

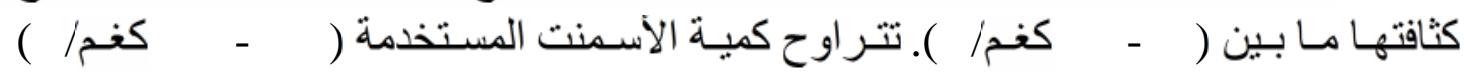

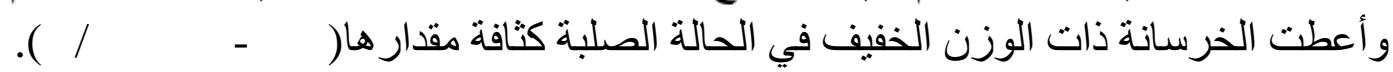

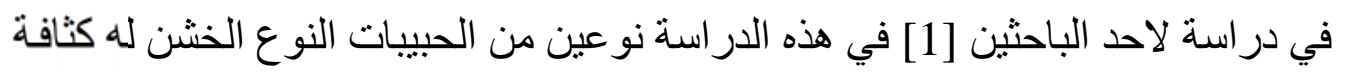

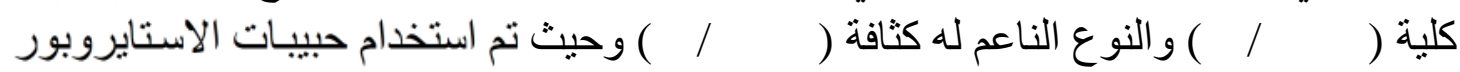

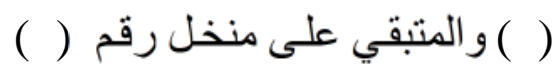

لعملية المزج مع نموذج للتربة وبكثافة تقدر ( ل الانتاج لبنة طبنية خفيفة

المضافات استخدمت من قبل بعض الباحثين لتجنب الانعز ال في الخلطات الخرسانية

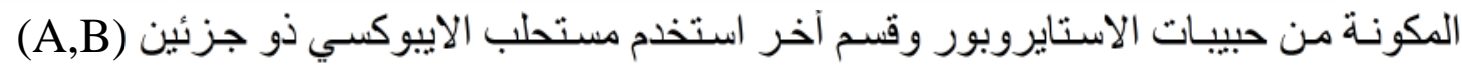

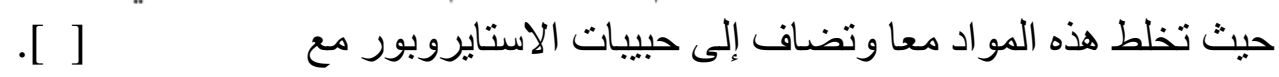

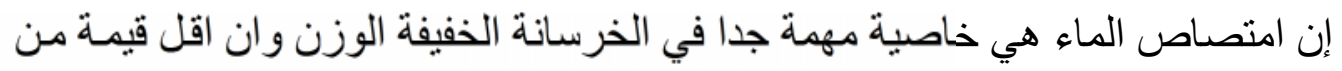

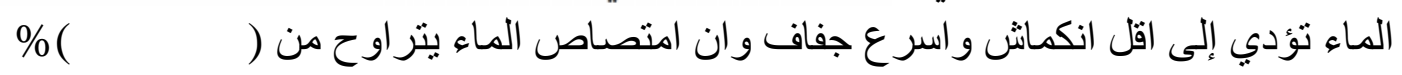
.[ ]

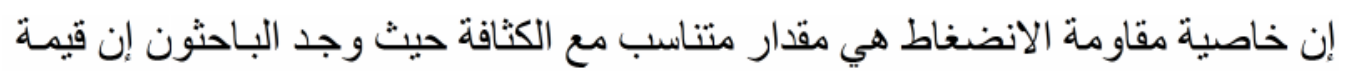

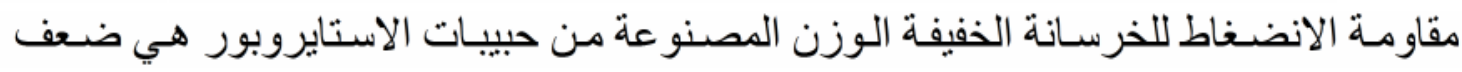

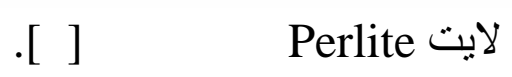

إن القص و الانثناء ذات سلوك معين في العتبات الخرسانية

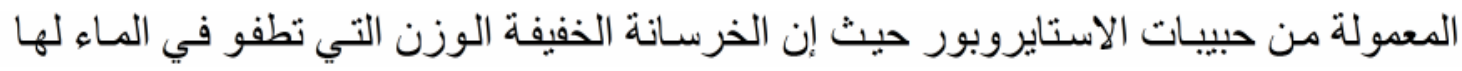

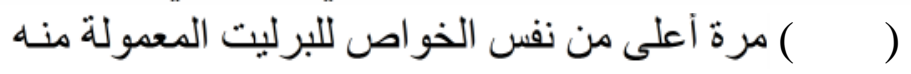
الخرسانة ولنفس الكثافة الوزنية. 
إن الهـدف مـن البحثث هـ در اسـة إمكانبـة اسـتخدام حبيبـات الاسـتايروبور في خلطـة

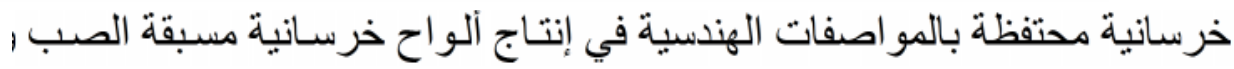

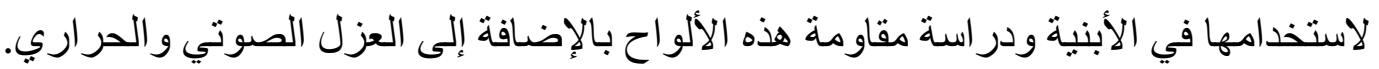

ـ استخدام سمنت من نوع بورتلاند اعتيادي من إنتاج معمل بادوش في الموصل وجبـة نشرين ـ استعمل الرمل المتوفر محليا من منطقة الكنه وظهر نجاحه بالتدرج مع وزن نوعي . . - حبيبات الاستايروبور المارة من منخل رقم ( ) ومتبقية على المنخل رقم ( ). ـ استخدم الماء الصالح للشرب و اثبت تحليله انه ضمن المو اصفات. - استخدم نو عين من حديد التسليح هما: ـ قضـبان حديـد محززة بقطر ( ملـم) وبإجهـاد خضـوع يسـاوي ميكاباسـكال عند

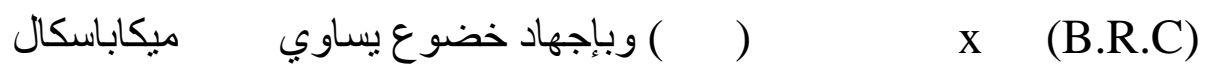

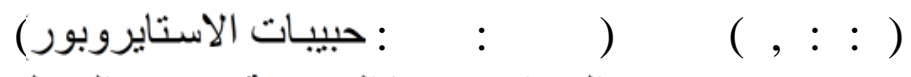

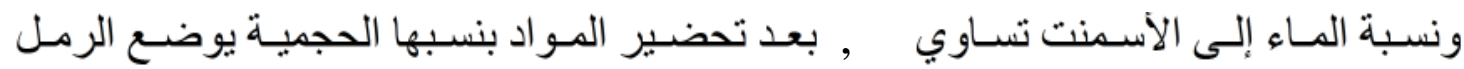

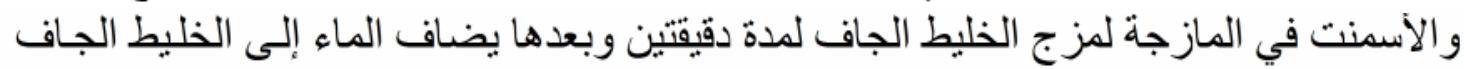

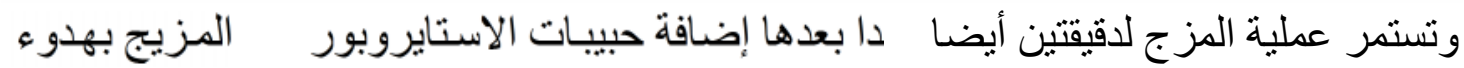
لتجنب حدوث التكتلات في حبيبات الاستايروبور. 
100x 100 x 0

$$
\text { يوم و عثر سنوات }
$$

نية بأبعاد 500 x 100x 100

$$
\text { يوم و عشر سنوات }
$$

ب ب ب $\quad 0$ x $\quad 0$

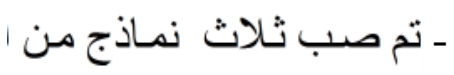

$(,::)$

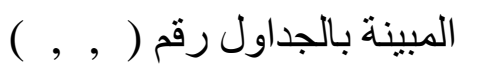

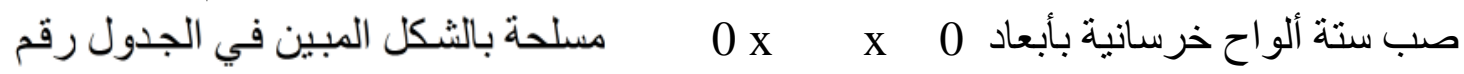

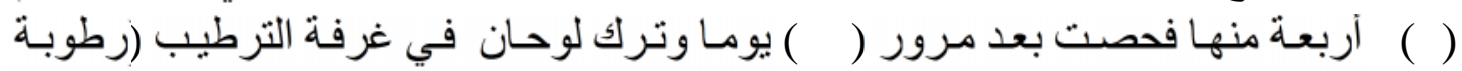

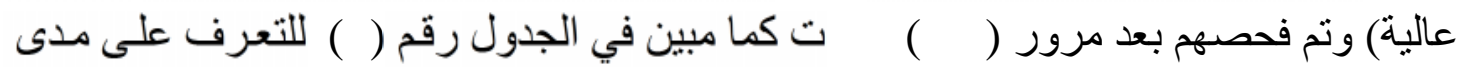

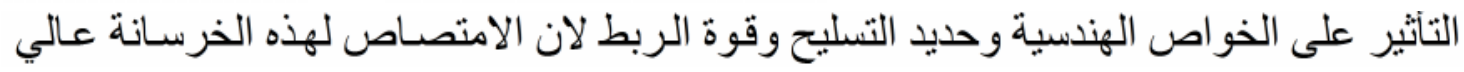

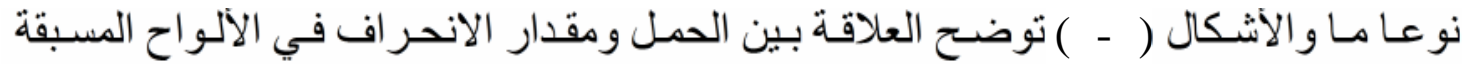

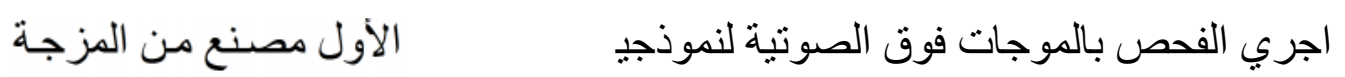

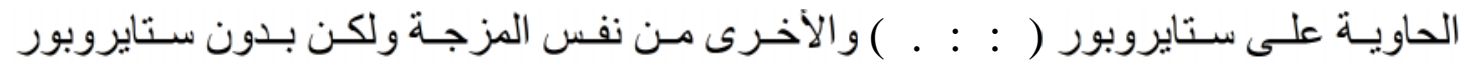

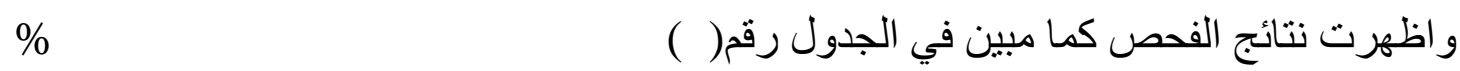

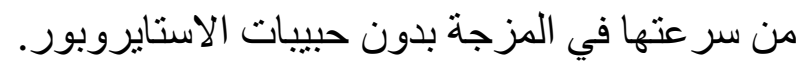

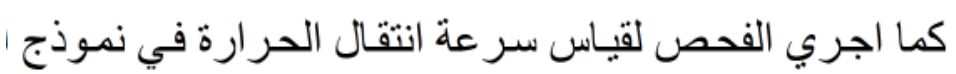

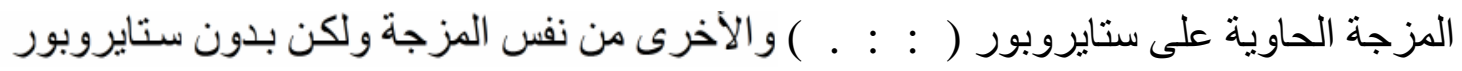

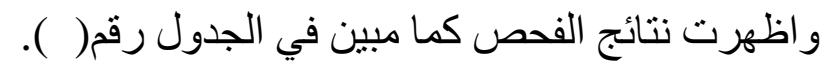

\begin{tabular}{|c|c|}
\hline / ميكاباسكال بعمر يوما & I \\
\hline & \\
\hline
\end{tabular}




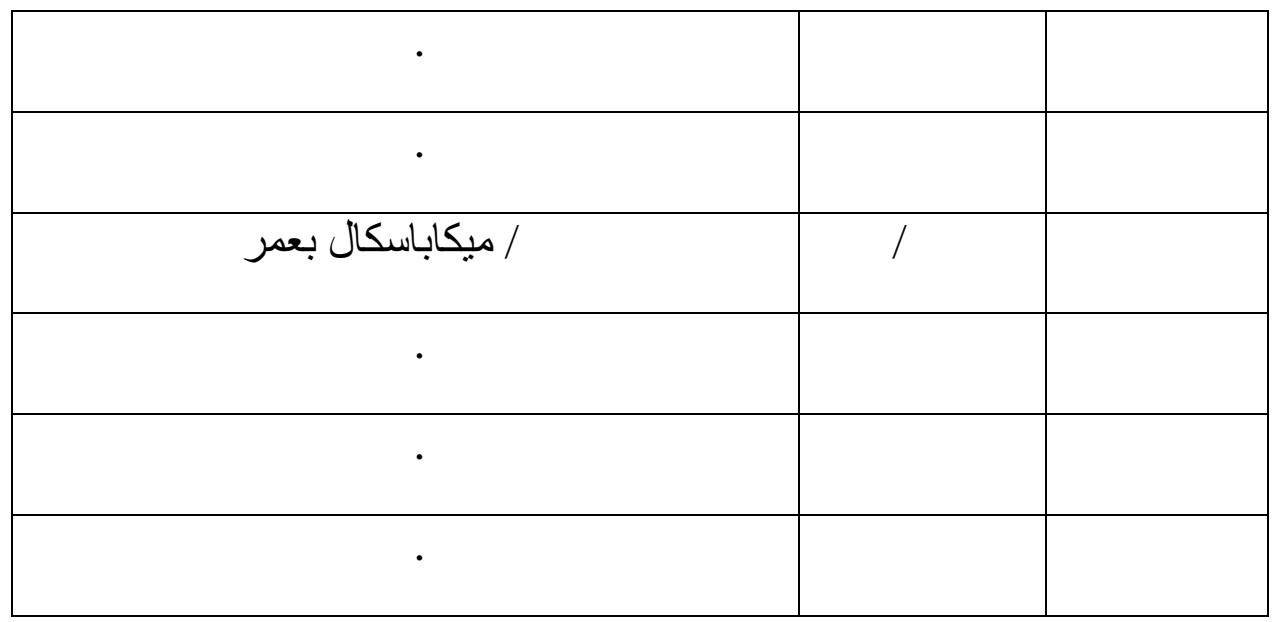

( )

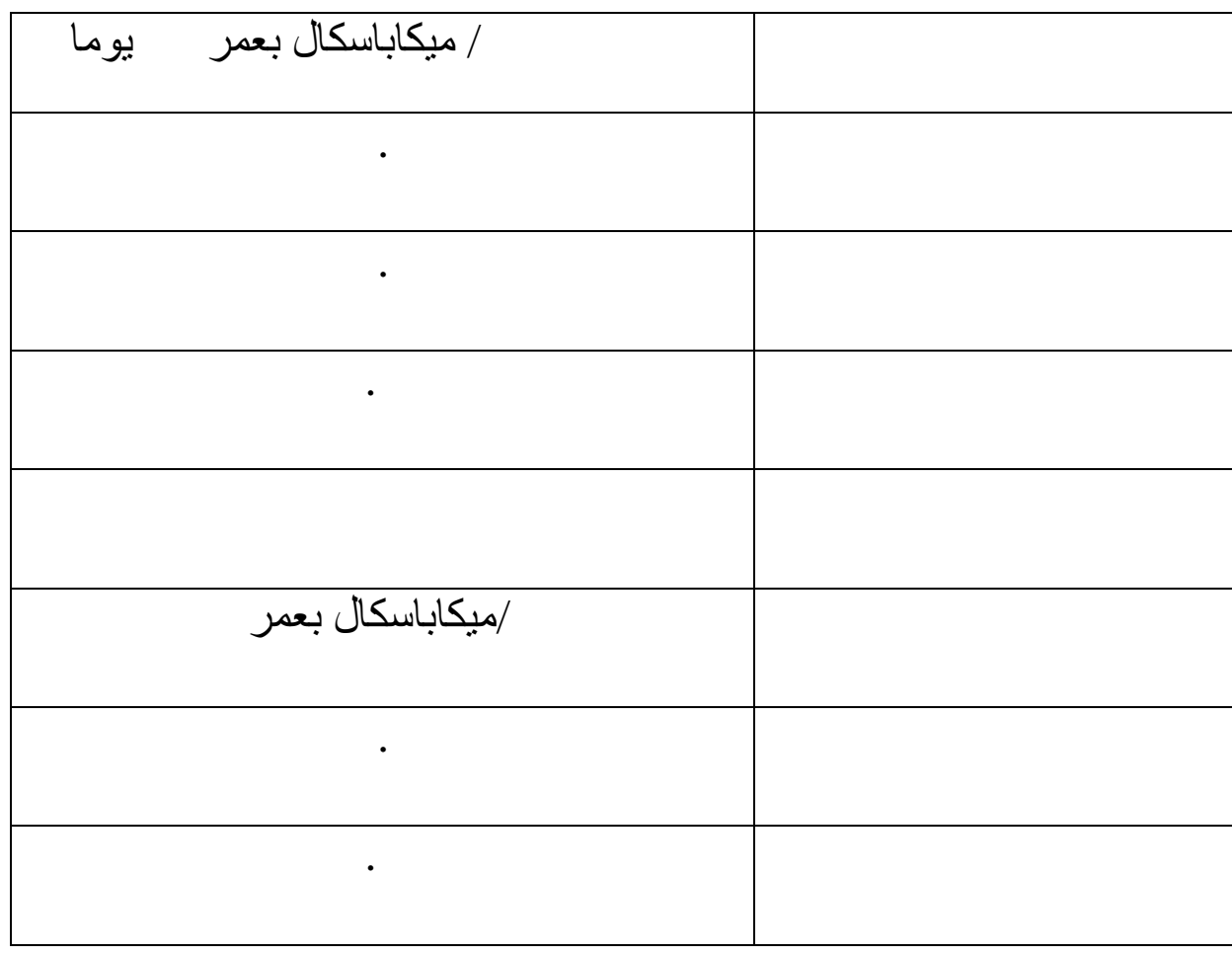

( )

\begin{tabular}{|l|c|c|}
\hline$\%$ & معاير الكسر/ميكاباسكال & \\
\hline & $\cdot$ & \\
\hline
\end{tabular}




\begin{tabular}{|c|c|c|}
\hline$\cdot$ & $\cdot$ & \\
\hline$\cdot$ & $\cdot$ & \\
\hline & & \\
\hline
\end{tabular}

$$
\text { ( ) نماذج الألواح الخرسانية }
$$

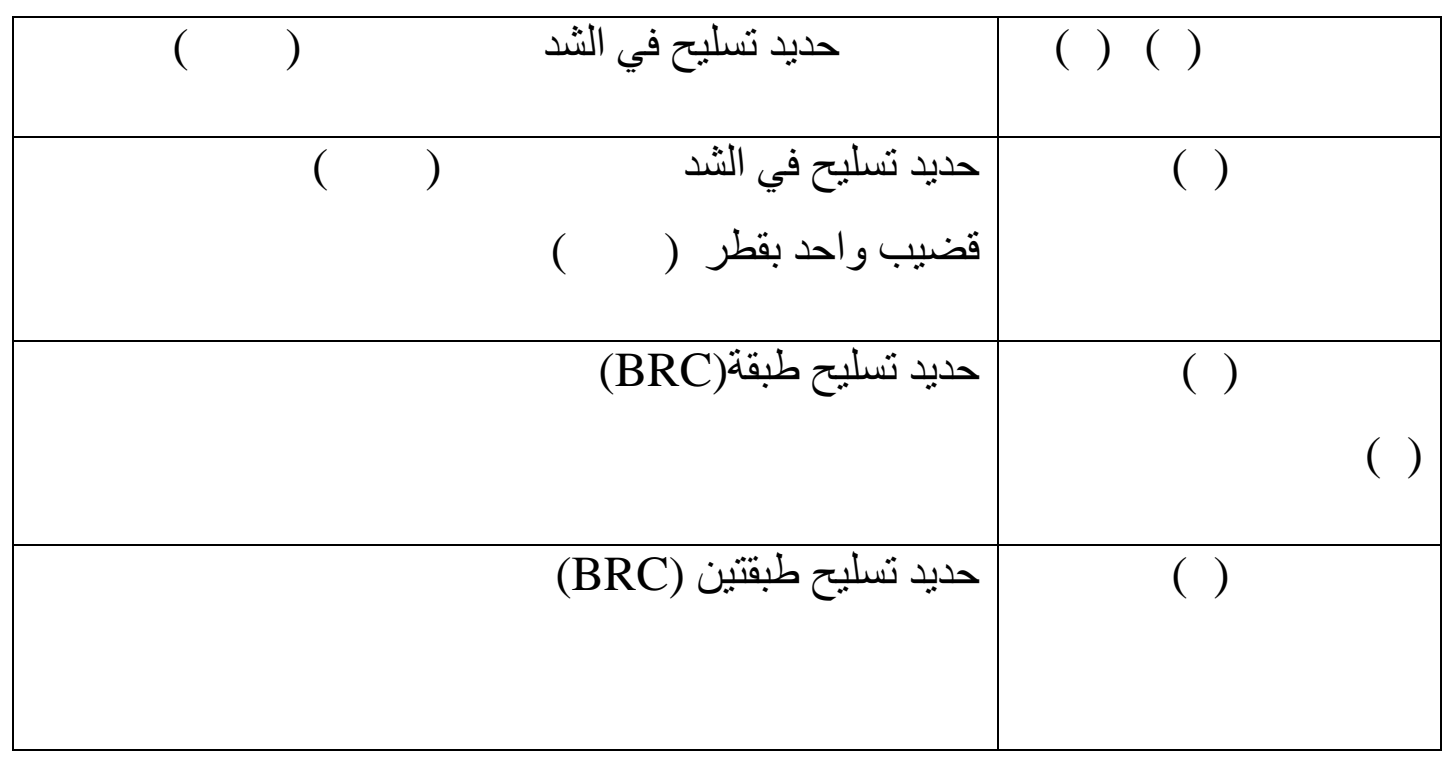

$$
\text { ( ) نتائج فحص الألو اح الخرسانية }
$$

\begin{tabular}{|c|c|c|c|c|}
\hline & $\mathrm{kN}$ & & $\mathrm{kN}$ & \\
\hline - & 32.8635 & 2.8 & 19.614 & ليوم \\
\hline 5.45 & 37.278 & 4.1 & 29.421 & يوم \\
\hline 11.4 & 22.563 & 4.94 & 19.614 & يوم \\
\hline . & 25.506 & 2.65 & 14.711 & يوم \\
\hline 9.78 & 35.316 & 3.15 & 22.066 & \\
\hline 12.39 & 24.525 & 5.43 & 21.575 & \\
\hline
\end{tabular}




\begin{tabular}{|l|r|}
\hline$/$ & \\
\hline & مزجة \\
\hline & مزوة بدون حبيبات الاستايروبور حبيبات الاستايروبور \\
\hline
\end{tabular}

( ) ) نتائج فحص نماذج الاشتايكر لقياس سرعة انتقال الحرارة

\begin{tabular}{|c|c|}
\hline مزجة & \\
\hline 0.254 & مزة حاوية على حبيبات الاستايروبور 1 k \\
\hline 0.372 & \\
\hline
\end{tabular}

- يمكن الحصول على توزيع متجانس للحبيبات في الخرسانة باستخدام أسلوب المزج في هذا

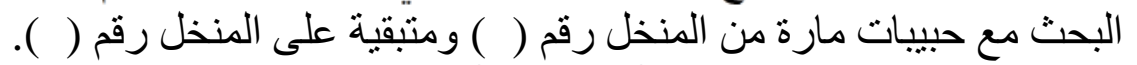

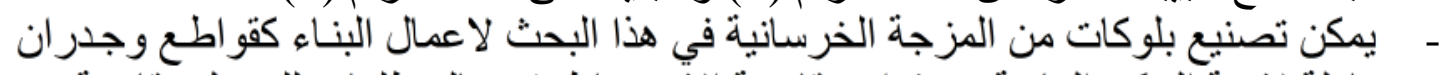

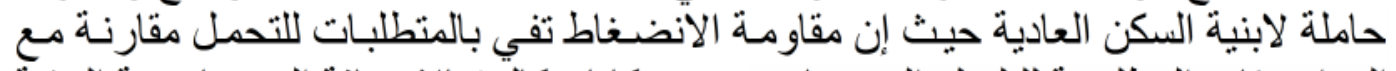

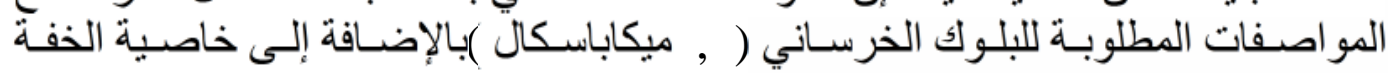

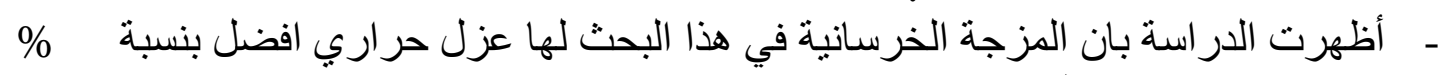
لخرسانة الاعتيادية.

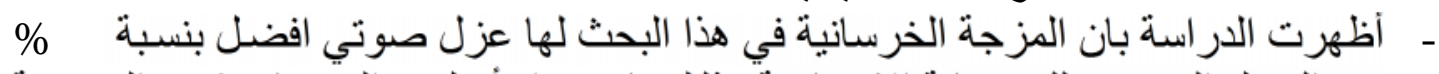

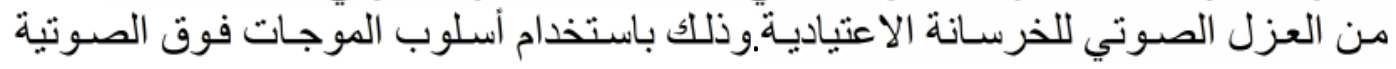

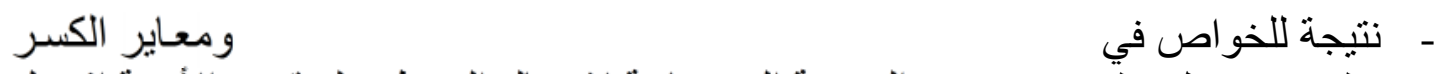
يظهر إن عمل قطع من المزجة الخرسانية لاعمال التسطيح لسقوف الأبنية افضل الفيل المستخدمة حاليا. 


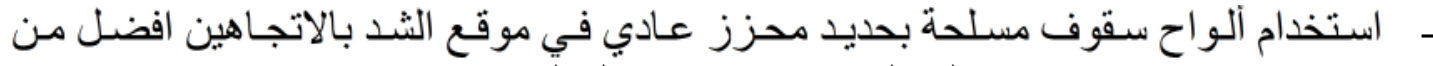

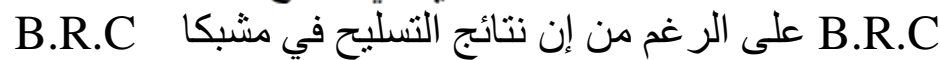

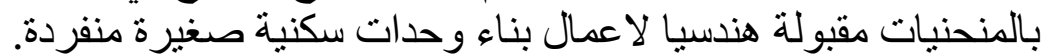

- م لم يحصل تشوه أو ضعف في المقاومة أو ضعف في قوة الربط بين الخرسانة وحديد التسليح

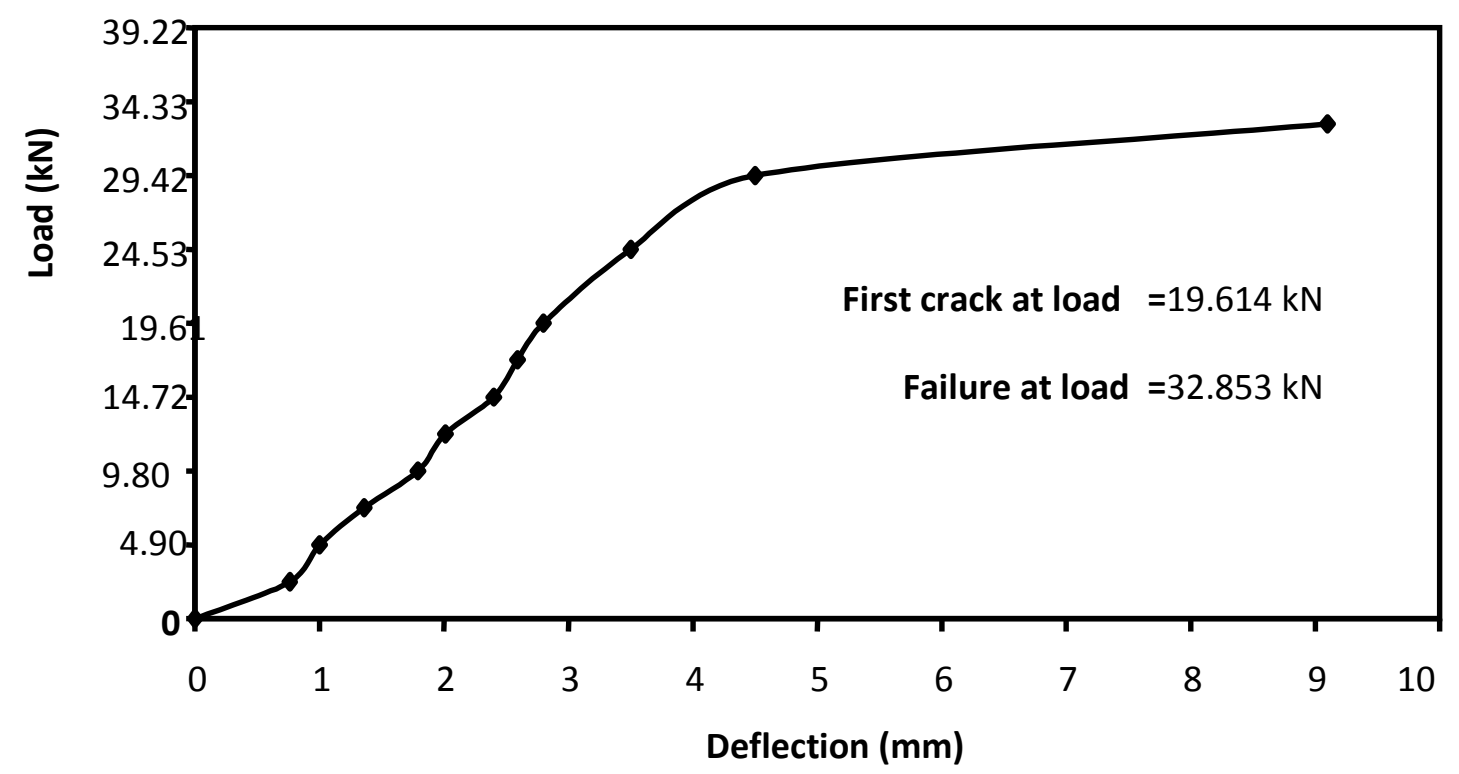

Fig. (1) Load deflection relationship for slab No.1

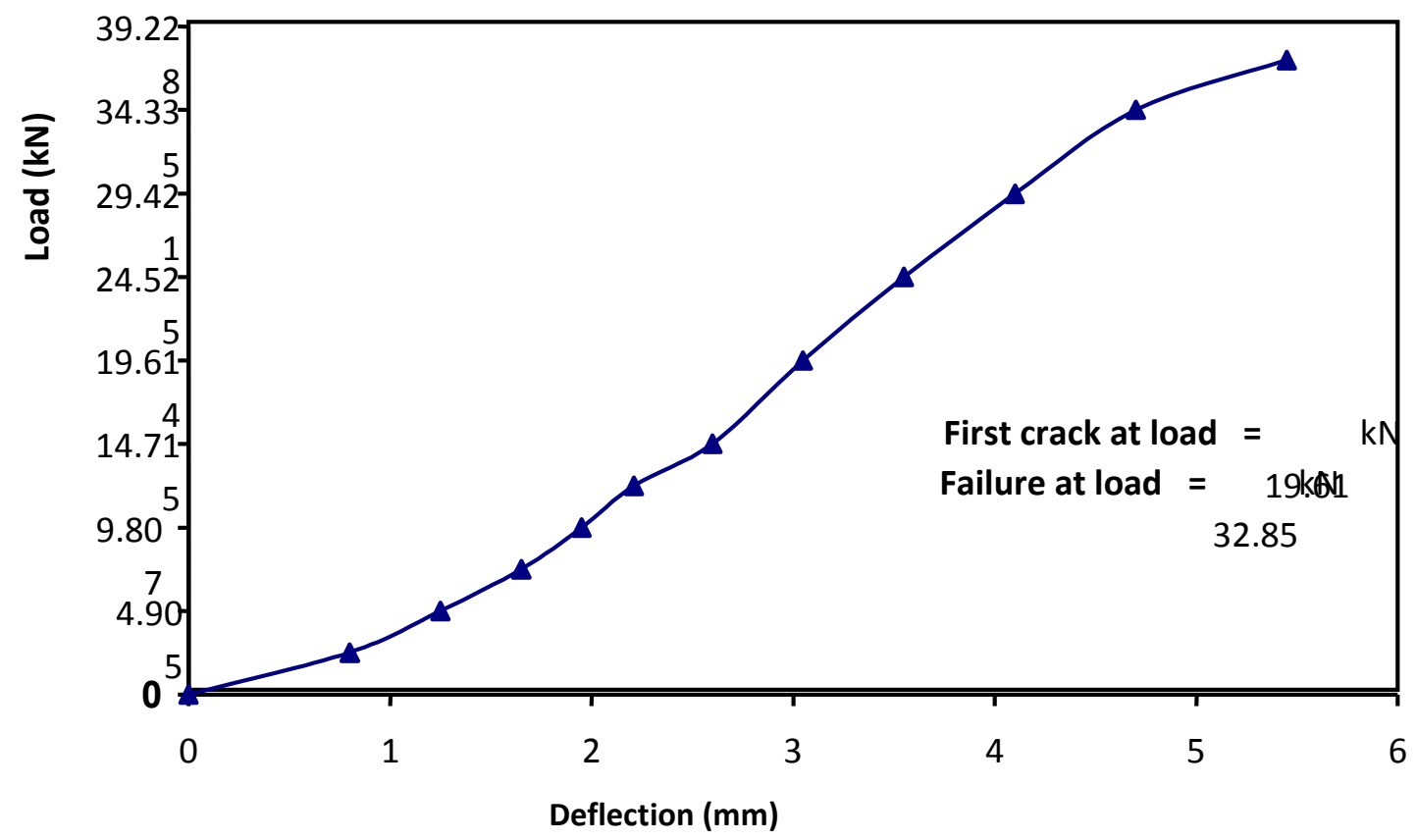

Fig. (2) Load deflection relationship for slab No.2 


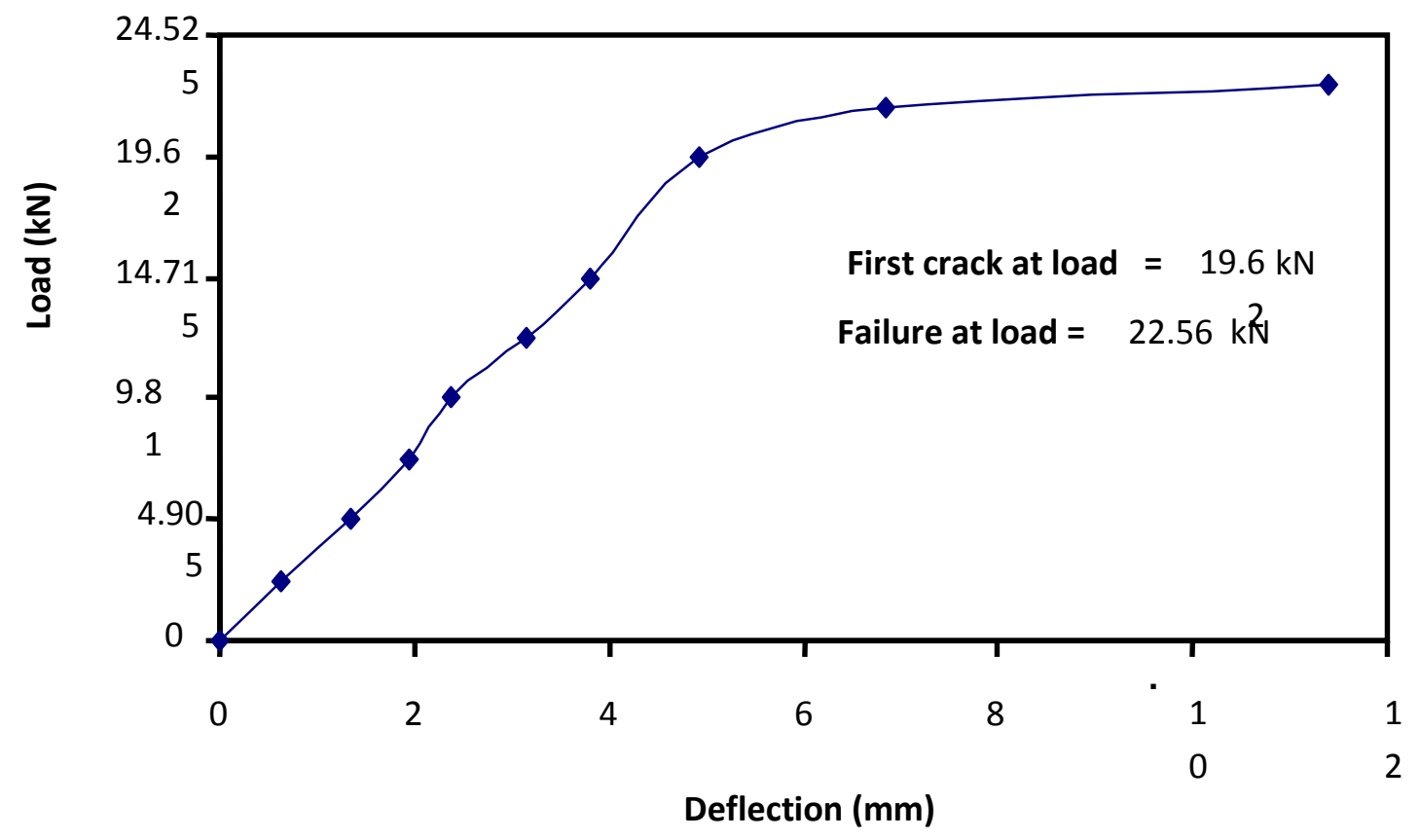

Fig. (3) Load deflection relationship for slab No.3 


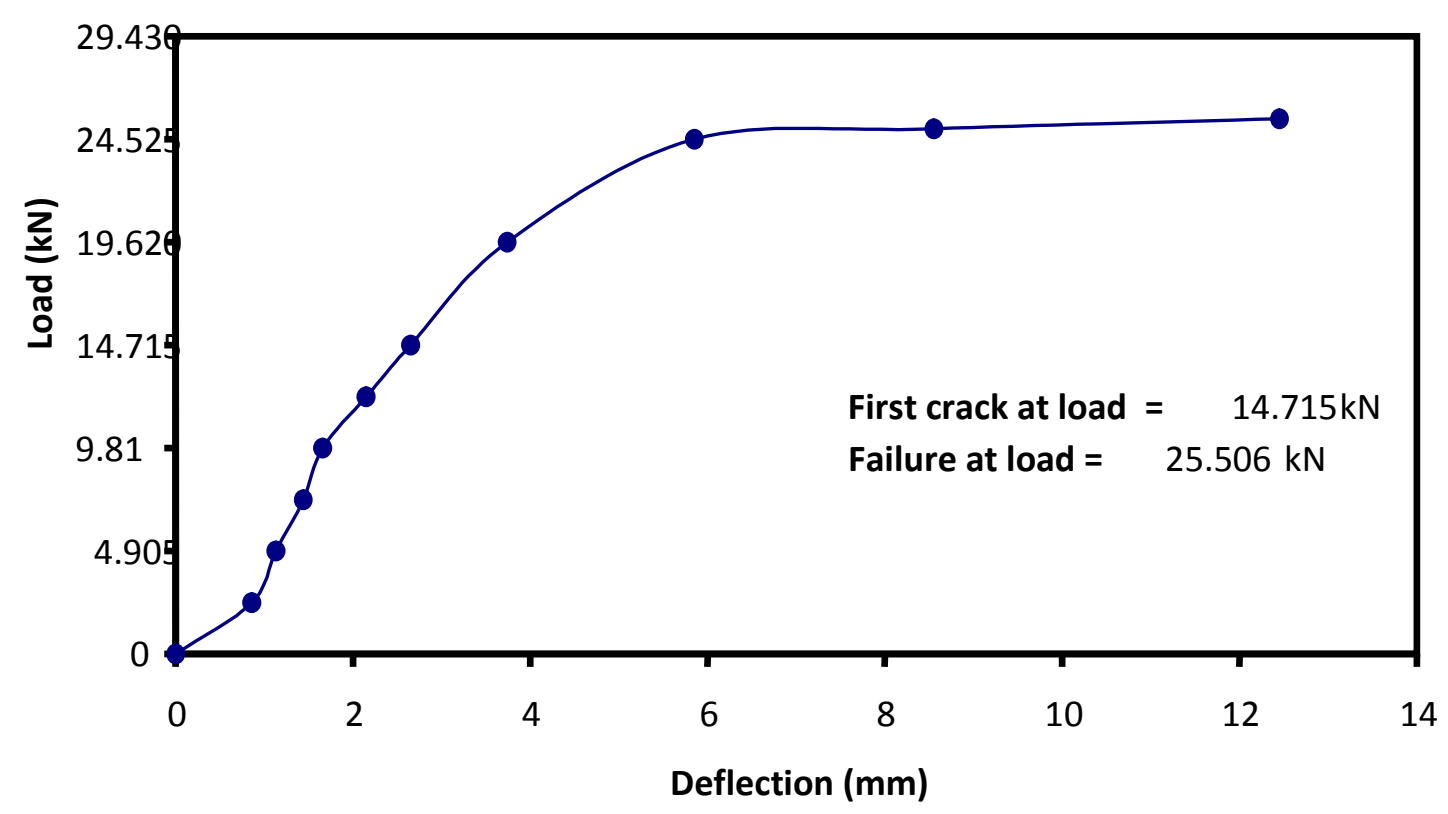

Fig. (4) Load deflection relationship for slab No. 4.

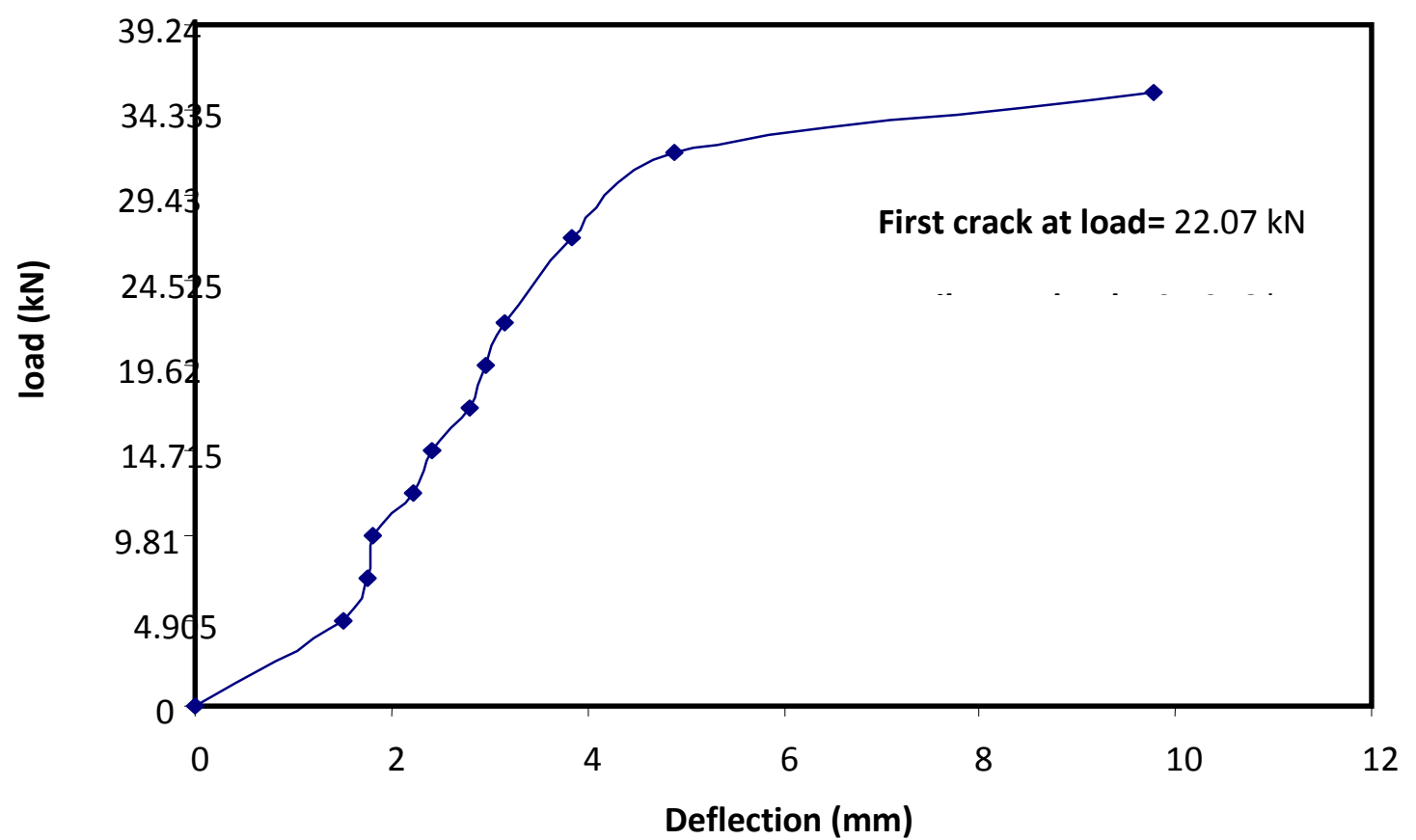

Fig. (5) Load deflection relationship for slab N.05. after 10 years 


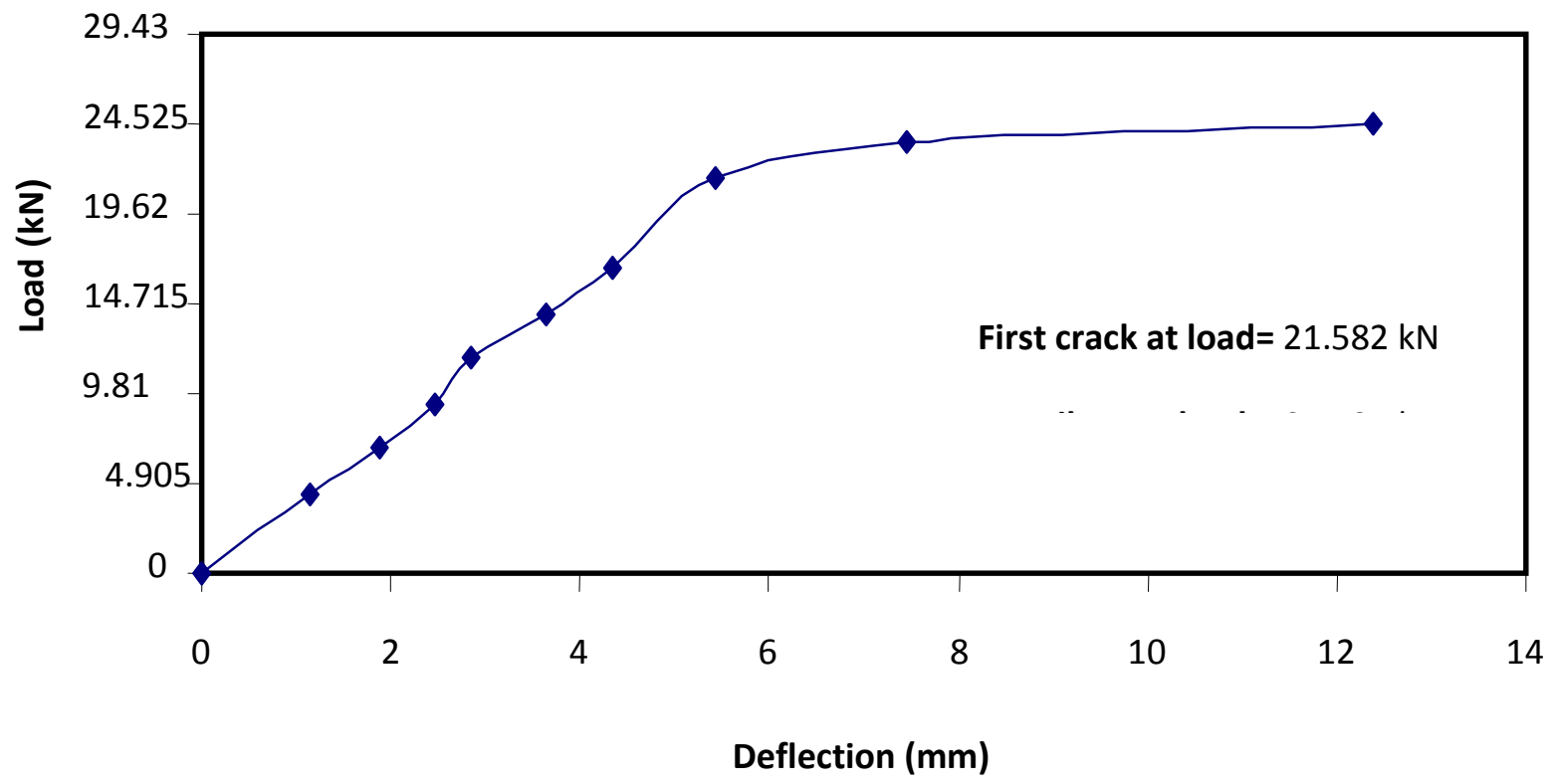

Fig. (6) Load deflection relationship for slab No. 6 after 10 years.

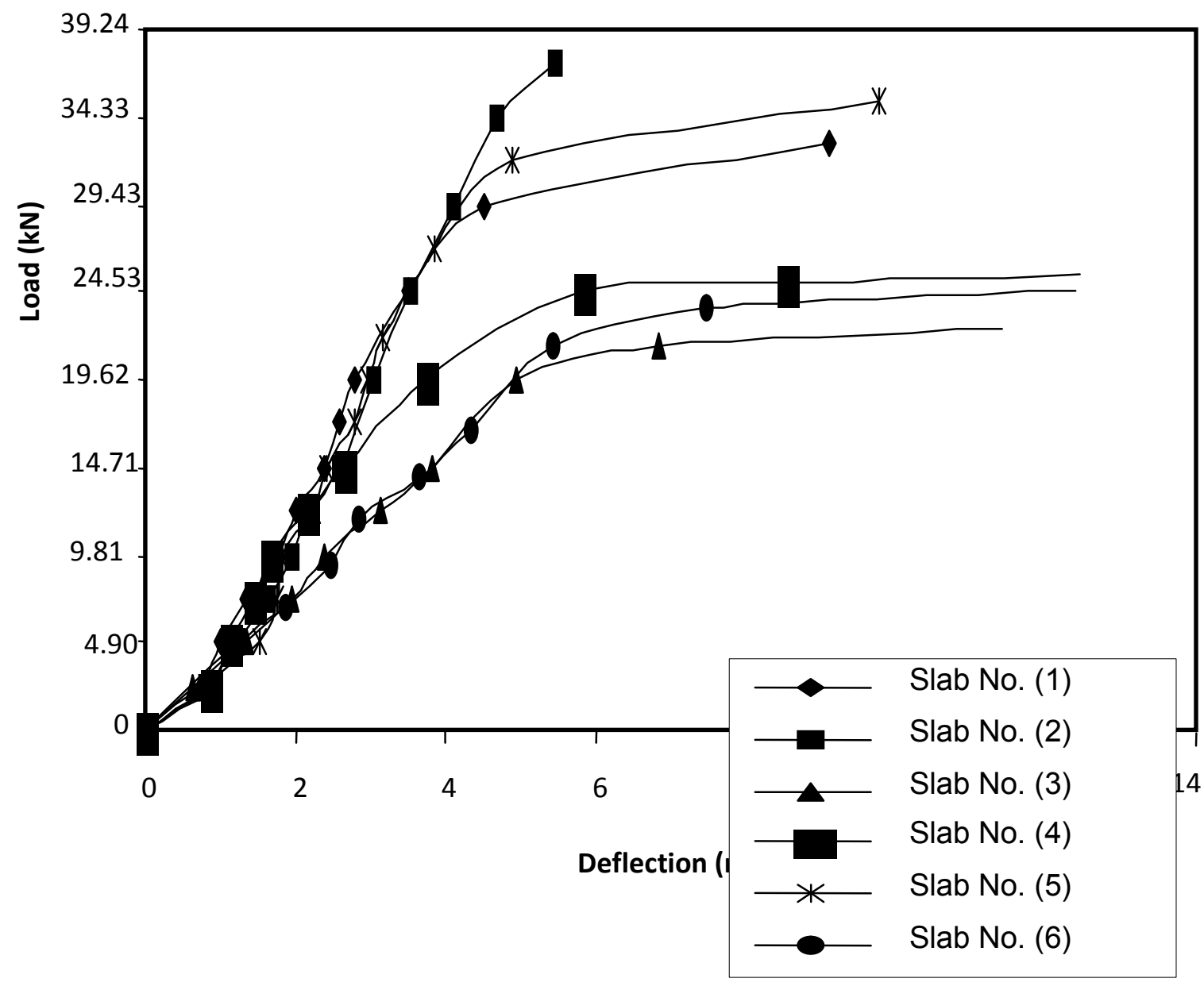


Fig. (7) Load deflection relationship for slabs (s1,s2,s3,s4,s5,s6) 